\title{
Thawing permafrost poses environmental threat to thousands of sites with legacy industrial contamination.
}

\section{Moritz Langer ( $\sim$ moritz.langer@awi.de)}

Alfred Wegener Institute Helmholtz Centre for Polar and Marine Research https://orcid.org/0000-00022704-3655

\section{Thomas Schneider von Deimling}

Alfred Wegener Institute Helmholtz Centre for Polar and Marine Research

\section{Sebastian Westermann}

University of Oslo

\section{Rebecca Rolph}

Alfred Wegener Institute Helmholtz Centre for Polar and Marine Research

\section{Ralph Rutte}

Freelancer https://orcid.org/0000-0002-0925-6446

\section{Volker Rachold}

Alfred Wegener Institute Helmholtz Centre for Polar and Marine Research

\section{Michael Schultz}

Heidelberg University

\section{Guido Grosse}

Alfred Wegener Institute Helmholtz Centre for Polar and Marine Research https://orcid.org/0000-00015895-2141

\section{Article}

Keywords: Contamination, Permafrost thaw, Environmental risks, Arctic climate change

Posted Date: March 2nd, 2022

DOI: https://doi.org/10.21203/rs.3.rs-1389869/v1

License: (c) (1) This work is licensed under a Creative Commons Attribution 4.0 International License. Read Full License

Version of Record: A version of this preprint was published at Nature Communications on March 28th, 2023. See the published version at https://doi.org/10.1038/s41467-023-37276-4. 


\section{Abstract}

Permafrost thaw is expected to become widespread in this century, threatening Arctic ecosystems, communities, and infrastructure. To date, industrial contaminants that have accumulated in Arctic permafrost regions have largely been neglected in climate impact analyses. Using publicly available data, we estimate that more than 10,000 contaminated sites originate from industrial activities in Arctic permafrost regions. We find a wide range of toxic substances, most of which are associated with industrial activities in mineral exploration and extraction, processing, and energy. By 2050 to 2100, climate change will significantly increase the risk of pollution and mobilization of toxic substances by exposing 500 to 1,500 additional known industrial sites and 1,000 to 3,500 estimated contaminated sites to permafrost degradation. Our analysis points to the severe environmental hazard posed by the legacy of past and ongoing industrial activities in the Arctic, which will be exacerbated by permafrost thaw.

\section{Introduction}

\section{Industrial legacies as a source of contamination in permafrost regions}

The Arctic is warming rapidly at rates two to three times faster than the rest of the globe (1). The warming causes widespread and accelerated thawing of permafrost $(2,3)$, substantially changing the ground stabilities and hydrological conditions $(4,5)$. A recent review highlighted the potential of new biogeochemical risks that could be associated with permafrost thawing and the mobilization of hazardous substances from various sources (6). At the same time, there is clear evidence of increasing risk to the stability of infrastructure in permafrost regions $(7,8,9)$, which was built on the premise of permanently frozen ground. The latest environmental disaster attributed partially to this loss of ground stability (10) was the giant diesel spill near the industrial city of Norilsk in northern Siberia in May 2020, where approximately 20,000 tons of fuel spilled from a destabilized tank facility and ended up in the Arctic ecosystem polluting streams, lakes and tundra in the large downstream watershed.

Over the course of decades, industrial and economic development of the Arctic was based on the assumption that permafrost will serve as a permanent and stable platform (11). Past industrial practices also assumed that permanently frozen ground and its properties as a hydrological barrier functions as a long-term containment for solid and liquid industrial waste $(12,13,14)$. These widespread practices across the Arctic have led to the accumulation of various toxic substances on or in permafrost ground. Known industrial waste types found in the Arctic include, but are not limited to, drilling and mining remains, toxic substances like drilling muds and fluids, mining heaps, heavy metals, spilled fuels, and radioactive waste (Fig. 1 and SI Appendix, Table S1). Scientifically documented methods for dealing with such substances in remote Arctic regions during much of the 20th century include creating covered waste dumps in permafrost, covered drilling mud sumps, using hydrologically closed lakes and basins as natural dumps, and spreading substances across a large area for dilution in the belief that permafrost underneath and in the surrounding will serve as a stable barrier for waste containment of infinite duration $(15,16)$. Several experiments that involved inducing toxic liquids and solids directly into permafrost, even 
including radioactive waste, were carried out in Alaska, Canada, and Russia $(17,18,19)$. The extent of this environmental impact for the entire Arctic has not yet been estimated.

Here we present the first panarctic estimates on the number of industrial sites and their various types of toxic substances left from industrial activities in permafrost regions. We further use different future climate scenarios to evaluate how many and when these sites will be affected by permafrost thaw. We show that industrial legacy sites on thawing permafrost and the mobilization of toxic substances likely pose a significant environmental risk that has not yet been assessed quantitatively on the panarctic scale due to limited available data. Our initial estimate suggests that the risks posed by legacy industrial sites in permafrost regions are significant and require better management strategies and access to industry data. The additional impacts of uncontrolled gradual or rapid mobilization of toxins have to be considered in site-specific impact assessments, which already indicate that permafrost thaw will significantly increase the costs of infrastructure maintenance, replacement, relocation, logistics, and adaptation $(7,8,20,21)$.

\section{Results}

\section{Hazardous substances and number of affected sites in permafrost regions}

Despite the lack of detailed information, we generated synergized geospatial data (see Methods) on industrial land use (see Methods) that allow us to estimate the magnitude of industrialisation and its spatial pattern in the Arctic. Our database shows that about 4,300 land use elements labeled 'industrial' (hereafter called 'industrial sites') are located in the Arctic on continuous or discontinuous permafrost ground (Fig. 2). Following the classification scheme for industrial sectors of the International Panel of Climate Change (IPCC), we find that most industrial sites ( 65\%) are either unlabeled or cannot be attributed to one of the four major IPCC sectors ('Agriculture, Forestry and Other Land Use'; 'Energy'; 'Industrial Processes and Product Use'; 'Waste'), which illustrates the immense lack of information on hazardous industrial substances in the Arctic. Among the clearly labeled data, the 'Energy' sector and the class 'Agriculture, Forestry and Other Land Use' are the most dominant (both $>10 \%$ ) in permafrost regions.

The available data on Arctic industrial sites provide neither quantitative nor qualitative information on the associated contamination potential. We therefore use available data from Alaska (Contaminated Sites Program, CSP (23)), which enables us to assess the magnitude and type of contamination in relation to industrial sites (Fig. 3). The analysis of the CSP database shows about 8,000 individual contaminated sites (until January 2021) for Alaska alone. About 17\% $(\sim 1,400)$ of these sites are located in areas characterized by continuous or discontinuous permafrost and more than $60 \%(\sim 850)$ of the contaminated sites are explicitly associated with industrial or military activity. Within the permafrost zone, about 330 contaminated sites are labeled as active and 180 contaminated sites are labeled as under institutional control, indicating that hazardous substances remained in the environment even after 
cleanup. The CSP database further reveals that the number of registered contaminated sites had its maximum in the 1990s, which has decreased from about 90 registrations per year in 1992 to 38 registrations per year in 2019, roughly following the evolution of crude oil production on the Alaska North Slope (Fig. 3, inset figure). This example clearly shows that 20th century industrial development in Alaska has led to an accumulation of contamination that very often remained at the sites.

According to the absolute occurrence of industrial sectors in the CSP data (SI Appendix, Fig. S1) we expect a large fraction of the existing contaminations to originate from the sectors of 'Industrial Processes and Product Use' ( 30\%) and 'Energy' ( 25\%). It is striking that both sectors are responsible for more than $50 \%$ of the contaminations, but together make up only about $16 \%$ of the industrial sites in the permafrost region in Alaska. The CSP data reveal that fuels such as diesel, kerosene, gasoline and associated chemicals make up by far the largest fraction (about 50\%) of the substances found at contaminated sites in the Alaskan permafrost region (Fig. 4 and SI Appendix, Fig. S2). Substances with high aquatic toxicities such as mercury, lead, and arsenic are amongst the top twenty of the most frequently listed substances in the CSP database. We emphasize that about $40 \%$ of the industrial sites, about $20 \%$ of the contaminated sites, and about $10 \%$ of the substances are labeled as unknown or not attributable in our database so that any relational analysis between these categories is highly uncertain. Our analysis, however, allows a first-order assessment of the magnitude and properties of contaminated sites in Alaskan permafrost, highlighting the large amounts of hazardous substances that remain as legacy of industrial activities.

Performing a spatial cross-analysis (see Methods), relating the locations of industrial sites and contaminated sites in Alaska, revealed that the location of industrial sites can provide a first-order estimate on where dangerous substances can be expected (Fig. 5a). To estimate the total number of industrially contaminated sites located in Arctic permafrost, we made the assumption that the CSP data from Alaska can be considered a representative subset for the entire panarctic. We found a strong spatial relationship between the density of industrial sites and the occurrence of contamination and assume that the risk of contamination is largely determined by the presence of industrial sites. We note that it is not currently possible to account for country-specific differences due to scarce data availability.

We extrapolated the total number of contaminated sites by applying the ratio between contaminated sites and industrial sites found for Alaska, which yielded more than 14,000 contaminated sites for the Arctic permafrost regions. Independent statistical projections based on Poisson point process models fitted to the CSP data (Fig. 5b, Fig. S5) indicated a similar total count of about 11,000 contaminated sites that potentially exist in continuous and discontinuous permafrost across the Arctic. However, we emphasize that the occurrences of contaminations in the Arctic likely show strong regional differences, depending on the industrial sectors active in these regions, national environmental legislation, and its enforcement during different time periods. Lacking detailed regional information, these dependencies are clearly not captured by our upscaling approach. A more detailed analysis of the contamination potential would require (i) a dataset similar to CSP for the entire Arctic and (ii) a characterization and quantification of 
contaminant stocks including storages as well as intentional or accidental disposal, covering the entire range from small fuel spills to major contamination of the magnitude of the 2020 Norilsk event.

\section{Rapidly growing number of sites affected by progressing permafrost thaw}

We applied a numerical permafrost model (see Methods), driven by past climate data and future projections, to quantify how present and future permafrost thaw affect industrial and contaminated sites (Fig. 5c). In our model, permafrost is considered to degrade when simulations indicate the formation of a year-round unfrozen ground layer. The simulations reveal that about $65 \%$ of the currently existing industrial sites $(\sim 3,000)$ and the estimated contaminated sites $(\sim 6,500)$ are located in the zone of discontinuous permafrost, which is characterized by permafrost degradation under present climate conditions. According to the simulations, more than $65 \%$ of these industrial sites $(\sim 2,000)$ and contaminated sites $(\sim 4,500)$ are located in regions where a change from continuous (stable) to discontinuous (degrading) permafrost occurred relatively recently between 1950 and 2000. The rapid increase of sites located on degrading permafrost over the end of the 20th century is due to a spatial clustering of industrial and contaminated sites in the southern permafrost region (SI Appendix, Fig. S3) affected by permafrost thaw when global warming exceeded a level of about $0.5^{\circ} \mathrm{C}$ above pre-industrial conditions (1850-1900) (Fig. 5d). On the one hand, it is likely that some of these sites were already permafrost free at the time of infrastructure construction, so that further warming would not affect their stability. On the other hand, it is possible that at these locations permafrost and potentially ground ice still existed and degradation created ground instabilities and new hydrological pathways. At such sites, the risk of destabilization and contaminant mobilization due to permafrost degradation is largely unpredictable without detailed knowledge of the local ground stratigraphy and infrastructure design.

About $35 \%$ of the existing industrial sites $(\sim 1,500)$ and the estimated contaminated sites $(\sim 3,500)$ are currently located on stable (continuous) permafrost. The projections suggest that the future number of these sites on stable permafrost will decrease by about $5-30 \%$ within the coming 30 years, with moderate differences between a low (RCP 2.6) and a high (RCP 8.5) emission scenario. After 2050, however, the projections reveal pronounced differences between the warming scenarios. The number of industrial sites affected by permafrost degradation increases only slightly under a pathway consistent with the $2^{\circ} \mathrm{C}$ global warming target (RCP 2.6). In contrast, almost all existing industrial sites and contaminated sites will be located in regions affected by permafrost degradation under a "business as usual" scenario (RCP 8.5). This strong warming scenario results in widespread near-surface permafrost thaw, affecting almost the entire Arctic by 2100 (24). Our findings underline that considering timeframes beyond 2050 is essential for assessing risks related to failure of industrial infrastructure and thawmobilization of contaminants - a time horizon neglected in recent studies $(7,8)$, infrastructure planning and the management of contaminations.

The projections of permafrost degradation underline the problem of loss in the stability of most existing industrial sites and their risk for potential release of toxic legacies (contaminated sites). This is especially 
true for sites in operation before the 2000s, since thermal permafrost conditions have already changed drastically over the last two decades (2).

Our simulations underline the need for extending the time horizon of previous risk studies focusing on mid-century $(\lambda)$ for considering long-term consequences of permafrost degradation which can reach far into the second half of the $21 \mathrm{st}$ century. Our results indicate that staying below the $2^{\circ} \mathrm{C}$ global warming target may avoid a further rapid increase in the number of affected industrial sites and contaminated sites in the second half of the $21^{\text {stt }}$ century. The pronounced difference in the number of industrial sites affected by permafrost degradation between the two scenarios is mainly due to the specific latitudinal distribution of the industrial and contaminated sites (SI Appendix, Fig. S3).

Our estimate of the increase in the number of affected sites is conservative because it does not account for rapid permafrost thaw processes (e.g. thermokarst and thermal erosion) (4), the effects of infrastructure on permafrost thaw (25), or the effects of contamination (e.g., freezing point depression from dissolved substances) (26) on permafrost stability.

\section{Discussion}

Our analysis suggests that there are currently thousands of industrial sites located on degrading permafrost, which are exposed to the risk of partial or complete failure already today. Climate warming will increasingly aggravate the probability that toxic substances associated with such sites will be released due to the failure of critical facilities for waste, storage, and disposal ( 7 ). Permafrost thaw not only poses a risk for industrial infrastructure integrity and disposal areas, but will also open new hydrological pathways $(5,11,27)$ and reduce the accessibility of remote permafrost regions $(28)$. The thaw-induced changes in water flow pathways and hydrologic connectivity, will impact the release and the dispersion of contaminants, while loss of ground stability will limit the access to impacted sites and use of heavy equipment, both severely complicating mitigation and cleanup measures.

We emphasize that with the information currently available, it is not possible to directly assess the probability of toxic substances being mobilized by permafrost degradation. Permafrost thaw affects multiple factors that define the ecological, economic, and social risks caused by contamination (Fig. 6). Regarding risk as a combination of hazard probability (environmental changes or events that threaten the safe storage of industrial toxins on or in permafrost ground), vulnerabilities (factors that control the likelihood and severity of contamination in the case of a hazard), and exposed values (assets and other values that are threatened by contamination) reveals that all key factors demanded for a complete risk assessment are highly uncertain or unknown (29). This is either due to existing information being inaccessible to the public or information being fully lacking. Publicly accessible information about location, toxicity, and type of stored substances, and conditions and characteristics of storage facilities or other disposal settings is extremely limited. The regional example of the Contaminated Sites Program (CSP) in Alaska demonstrates the value of transparent documentation of contamination for sciencebased risk assessments. Only the availability of a global database would allow an improved panarctic 
estimate which accounts for country-specific aspects. Our results on the number of affected sites and their susceptibility to permafrost thaw provide a first order of magnitude estimate for assessing the vulnerability. Nevertheless, the overall risk appears to be largely unpredictable due to the broad lack of information on industrial sites in the Arctic, while at the same time the number of sites is rapidly growing due to an increasing economic activity in the Arctic (30). Without more detailed risk assessments, communities, stakeholders, and decision makers will be unprepared to potential future environmental disasters from gradual or abrupt release of contamination from industrial legacy sites due to permafrost thaw.

Whereas risks associated with municipal waste and how that is affected by climate change has received attention $(31,32)$, the risks of contamination from large-scale and gradual release of hazardous substances as a consequence of permafrost thaw are still poorly studied. Consistent with studies predicting the costs of infrastructure destabilization due to permafrost thawing $(8,9)$, the costs of securing contaminants, post-operational renaturation, and remediation following an accidental release of contaminants can be expected to increase sharply. Thus, there is a need to reconsider typical amortization periods for industrial activities in the Arctic.

Recently, (33) suggested mercury release as a potential threat from thawing permafrost, and (6) generally discusses bio-geochemical risks from permafrost thaw. We extend this discussion by considering risks and consequences of potential abrupt contamination from failure of industrial infrastructure built on permafrost (e.g., as happened for the Norilsk diesel tank accident). This type of risk shows a clear threshold behavior associated with reaching a critical ground temperature (34). As opposed to a steady release of contaminants such as mercury in soils triggered by large-scale permafrost thaw, the risk of abrupt contaminant release could often be managed by reducing site-level vulnerability. However, this requires operational monitoring systems which can deliver early warning information needed for timely infrastructure adaptation. While such technology-based mitigation strategies could be fairly straightforward when applied to new industrial facilities and sites that are currently in operation, seamless monitoring and remediation of industrial legacy sites appears rather unrealistic. Only few monitoring programs exist for legacy sites, such as for the Mallik Drilling site with its covered drilling waste sumps in the Mackenzie Delta of NW Canada; however, the observation period (7 years in this particular example) clearly needs to be longer to capture the time scales of thawing permafrost in the coming decades (35). We suggest that for contaminated industrial sites on permafrost, it is particularly important to reconsider time, effort, and financial resources required to meet official long-term site remediation that include postthaw scenarios. For most existing sites in the Arctic, the time period to consider may extend well into the second half of the 21 st century and beyond due to lingering thawing permafrost. Our initial assessment suggests that existing and legacy industrial sites in the Arctic will be increasingly impacted by climate change. The impacts of permafrost thaw with all its consequences such as loss of hydrological barriers, enhanced hydrological connectivity, and reduced ground stability will often happen after the operational lifetime of industrial sites. This emphasizes the need for clear plans for the removal of any remaining environmentally hazardous substances after the site is no longer in use, as the current permafrost can no 
longer be considered reliable containment. It also urges long-term remediation strategies for contaminated legacy sites that have already been closed but may still contain hazardous substances.

To avoid environmental hazards caused by permafrost thaw at thousands of industrial legacy sites in the Arctic, reliable long-term planning strategies for industrial activities in the Arctic and their legacies are required taking climate change impacts until the end of this century into account.

\section{Methods And Material}

\section{Geospatial database and analysis}

The total number of industrial sites located on permafrost was estimated using OpenStreetMap (OSM) in combination with a spatial dataset on industrial facilities from the Atlas of Population, Society and Economy in the Arctic (APSEA) provided by the Nordregio. OSM is a thematic, limitless open spatial database under continuous development with thousands of everyday modifications (36). Given the application of certain filters, specific themed applications like land cover can be extracted using OSM (37). For our study, we used all OSM objects that were either a node (point) or way (polygons only) and attributed with the key 'landuse' or 'building' and the value 'industrial' north of the $55^{\circ} \mathrm{N}$ latitude and extracted 90,018 areas, 108,427 buildings and 139 detailed facilities related to industrial activities.

The OSM data were complemented with the APSEA data providing additional data on industrial sites such as airports, ports, mines, pipelines, roads, and petroleum fields. To avoid double counting and resolve geometry conflicts between both datasets, we define buffer areas ( $1 \mathrm{~km})$ around all features as overlap merging criteria.

Identification of the distribution of the combined OSM-APSEA database by major permafrost presence was achieved by overlay analysis using the Northern Hemisphere Permafrost Map (NHPM) (24). Hence, sites characterized by a permafrost occurrence probability of more than $50 \%$ were kept within the database, resulting in a total of 5,234 entries. Semantic optimization of the database was done by a detailed word count analysis, removal of text duplicates and obsolete or non-relevant text characters. The database was summarized into four industrial sectors following the classification of the IPCC ('Agriculture, Forestry and Other Land Use', 'Energy', 'Industrial Processes and Product Use', 'Waste'). The majority of database entries remained unlabeled due to missing tags and were, thus, classified "Uncertain" together with tags not fitting into the other categories above. The resulting database enabled a first-order assessment of the spatial distribution and concentration of industrial sites. However, historic industrial sites such as fully or partially revegetated old drill pads and drilling sumps, covered landfills and features yet undetected by remote sensing, for instance individual borehole sites, might be absent within our database. Further, our database does not account for pipeline networks transporting oil, which span large distances across the Arctic. Considering the omission of aforementioned objects within the OSM-APSEA database, we have produced a conservative estimate of industrial sites. Completeness and availability of land description in OSM can vary temporally and spatially (38). 
Actual permafrost occurrence probabilities and zones of permafrost occurrence were extracted from the latest global permafrost map (22).

\section{Industrial sites and contamination potential}

In order to investigate the link between industrial sites and the potential occurrence of environmental contaminants we make use of a database provided by the Contaminated Sites Program (CSP) in Alaska published by the U.S. Department of Environmental Conservation (23). Besides geographic coordinates, the downloadable database contains site classification and information on the treatment status. Similar to the industrial sites, we have performed a semantic analysis of the site names in order to classify the contaminated sites according to their industrial origin ('Agriculture, Forestry and Other Land Use', 'Energy', 'Industrial Processes and Product Use', 'Waste'). Site names not fitting into any of these categories are labeled as "Others" while absent site names are labeled as "Uncertain" (SI Appendix, Fig. S4).

A hazard identification number provides access to web pages on which more detailed information is provided including a timeline of actions implemented as well as free-text site descriptions and chemical reports. For each contaminated site, the earliest date of the timeline was automatically extracted and used for further analysis. Frequencies of chemical substances listed in the CSP database were extracted semi-automatically using Levenshtein distances to identify keywords (39). The extracted keywords were matched with substances listed in the database of the Chemical Abstracts Service (CAS) of the Chemical American Society (https://commonchemistry.cas.org/). Aquatic toxicities were extracted from the Globally Harmonized Systems (GHS) database (GESTIS substance database, https://gestisdatabase.dguv.de/) as median lethal concentrations for fish ( LC $_{50}$ Fish 96h) and missing data were complemented by individual literature review.

In order to infer the probabilistic spatial relationship between the density of industrial sites and the occurrences of contaminations, we set up a point process model assuming a nonhomogeneous poisson process. Therefore, we derive a density map from the point dataset of industrial sites for the entire panarctic domain defined by continuous and discontinuous permafrost. We use a gaussian kernel with a bandwidth set to $50 \mathrm{~km}$ which turned out to be a good compromise between the preservation of spatial details and the number of sites considered after performing extensive tests with bandwidths ranging between $10 \mathrm{~km}$ and $100 \mathrm{~km}$. Here we test two basic inhomogeneous poisson models which are fitted to CSP point data filtered for industrial sites within the permafrost domain of Alaska using the point process modeling tools provided by R (SI Appendix, Fig. S5) $(40,41)$. The fitted models are applied to the panarctic industry density map in order to generate estimated intensity maps of contaminated sites (SI Appendix, Fig. S6). We point out that we implicitly assume the data subset of Alaska to be representative for the entire Arctic and that the relationship between industrial sites and contaminations follows an inhomogeneous Poisson process which is only partly true according to the observed intensity function (SI Appendix, Fig. S5). We approximate a total count of potentially contaminated sites by integrating the calculated intensity maps.

\section{Permafrost stability}


For evaluating the future development of the thermal state of permafrost, we used the one-dimensional, transient permafrost model CryoGrid, forced only by near surface air temperature and precipitation (42, 43). The applied climate forcing was based on ERA-Interim reanalysis data for simulating the thermal state of permafrost under historic and current climatic conditions, while future simulations were based on decadal monthly anomalies from the CCSM4 (44) and HADGEM2-ES (45) CMIP5 projections under RCP 2.6 and RCP 8.5 scenarios. The scenarios used span a wide range of warming of the terrestrial Arctic (excluding glaciated regions) ranging from $0.7^{\circ} \mathrm{C}$ to $8.0^{\circ} \mathrm{C}$ over a period from 2020 to 2100 . A long term model spin-up from 500 A.D. to 1979 was performed based on anomalies from paleo-climate simulations with the Mk3L climate model of the Commonwealth Scientific and Industrial Research Organisation (CSIRO) (46).

Data required to set ground stratigraphies were extracted from the Open-ECOCLIMAP global database of land surface parameters $(47,48)$. Soil organic carbon contents were extracted from the Northern Circumpolar Soil Carbon Database version 2 (49) and the thickness of the soil layer was determined according to the Gridded Global Data Set of Soil Thickness (50). Stratigraphies of soil physical parameters were derived using the parameterizations developed for the SURFEX land surface and ocean scheme (51). Water or ice saturation of the ground was adjusted according to a global water table product (52) with soil layers below the water table assumed saturated, and soil layers above water table set half-way between field capacity and porosity. Snow cover densities and compaction rates were parameterized with a bulk approach according to panarctic climate classes (53). Since the available parameter and forcing datasets represent regional averages rather than specific locations, we applied a coarse grid cell resolution of one degree. The modeling exercise performed should be considered a firstorder assessment since the simple one-dimensional simulation did not consider any uncertainties in model parameterization. Uncertainty in the forcing is considered by focusing on 2 CMIP5 models of comparatively low (44) and high (HADGEM2-ES (45)) projected Arctic warming which were run under a low (RCP 2.6) and high (RCP 8.5) emission scenario. The full spread of CMIP5 model projections is likely larger than our model range indicated in Fig. 5. Furthermore, we point out that the simulations did not take into account rapid thaw processes (2) which may be triggered by thawing excess ground ice and erosion $(4,34)$. Model code, parameter settings, and forcing data are accessible through Zenodo (10.5281/zenodo.5195538).

A strong indicator for permafrost degradation is the formation of a persistent year-round unfrozen layer in the ground, often being referred to as "talik formation". The performed simulations allow us to determine the moment of talik formation which occurs where summertime thaw depth exceeds wintertime freezeback for at least two consecutive years. We define a talik to exist if a soil layer of at least $0.10 \mathrm{~m}$ thickness remains unfrozen. This diagnostic is only applied to sites featuring permafrost, which means the profile of the annual maximum temperature has temperatures below $0^{\circ} \mathrm{C}$.

\section{References}


1.) Meredith, M. et al. Polar Regions. Chapter 3, IPCC Special Report on the Ocean and Cryosphere in a Changing Climate, 203-320 (2019).

2.) Turetsky, M. R. et al. Permafrost collapse is accelerating carbon release. Nature 569, 32-34 (2019).

3.) Biskaborn, B. K. et al. Permafrost is warming at a global scale. Nature communications 10(1), 1-11 (2019).

4.) Nitzbon, J. et al. Fast response of cold ice-rich permafrost in northeast Siberia to a warming climate. Nature communications 11(1), 1-11 (2020).

5.) Liljedahl, A. K. et al. Pan-Arctic ice-wedge degradation in warming permafrost and its influence on tundra hydrology. Nature Geoscience 9(4), 312-318 (2016).

6.) Miner, K. R. et al. Emergent biogeochemical risks from Arctic permafrost degradation. Nature Climate Change 11(10), 809-819 (2021).

7.) Hjort, J. et al. Degrading permafrost puts Arctic infrastructure at risk by mid-century. Nature communications 9(1), 1-9 (2018).

8.) Suter, L., Streletskiy, D. \& Shiklomanov, N. Assessment of the cost of climate change impacts on critical infrastructure in the circumpolar Arctic. Polar Geography 42(4), 267-286 (2019).

9.) Hjort, J. et al. Impacts of permafrost degradation on infrastructure. Nature Reviews Earth \& Environment 3(1), 24-38 (2022).

10.) Rajendran, S. et al. Vethamony, Monitoring oil spill in Norilsk, Russia using satellite data. Scientific Reports 11(1), 1-20 (2021).

11.) Dyke, L. D. Contaminant migration through the permafrost active layer, Mackenzie Delta area, Northwest Territories, Canada. Polar Record 37(202), 215-228 (2001).

12.) Straughn, R. O. The sanitary landfill in the Subarctic. Arctic 25(1), 40-48 (1972).

13.) French, H. M. Terrain, land use and waste drilling fluid disposal problems, Arctic Canada. Arctic 33(4), 794-806 (1980).

14.) Johnson, D. Use of engineered landfills for arctic mine site reclamation. In Proceedings of the Sixth International Conference on Mine Closure, 495-502. Australian Centre for Geomechanics (2011).

15.) Abou-Sayed, A. S., Andrews, D. E. \& Buhidma, I. M. Evaluation of oily waste injection below the permafrost in Prudhoe Bay field. In SPE California Regional Meeting. Society of Petroleum Engineers (1989). 
16.) Ayele, Y. Z., Barabadi, A. \& Barabady, J. Drilling waste handling and management in the High North. In 2013 IEEE International Conference on Industrial Engineering and Engineering Management, 673-678 (2013).

17.) Macdonald, R. W., Hamer, T., Fyfe, J., Loeng, H. \& Weingartner, T. AMAP Assessment 2002: The Influence of Global Change on Contaminant Pathways to, within, and from the Arctic. Arctic Monitoring and Assessment Programme (AMAP) (2003).

18.) Artamonova, S. Y., Kozhevnikov, N. O. \& Antonov, E. Y. Permafrost and groundwater settings at the site of "Kraton-3" peaceful underground nuclear explosion (Yakutia), from TEM data. Russian Geology and Geophysics 54(5), 555-565 (2013).

19.) Ananicheva, M. et al. Snow, Water, Ice and Permafrost in the Arctic (SWIPA): Climate change and the cryosphere. Arctic Monitoring and Assessment Programme (AMAP), (2011).

20.) Streletskiy, D. A., Suter, L. J., Shiklomanov, N. I., Porfiriev, B. N. \& Eliseev, D. O. Assessment of climate change impacts on buildings, structures and infrastructure in the Russian regions on permafrost. Environmental Research Letters 14(2), 025003 (2019).

21.) Melvin, A. M. et al. Climate change damages to Alaska public infrastructure and the economics of proactive adaptation. Proceedings of the National Academy of Sciences 114(2), E122-E131 (2017).

22.) Obu, J. et al. Northern Hemisphere permafrost map based on TTOP modelling for 2000-2016 at 1 km2 scale. Earth-Science Reviews 193, 299-316 (2019).

23.) CSP, The Contaminated Sites Program, Department of Environmental Conservation, Division of Spill Prevention and Response (2020), Available online: https://dec.alaska.gov/spar/csp/ (accessed on 07 July 2020).

24.) Koven, C. D., Riley, W. J. \& Stern, A. Analysis of permafrost thermal dynamics and response to climate change in the CMIP5 Earth System Models. Journal of Climate 26(6), 1877-1900 (2013).

25.) Raynolds, M. K. et al. Cumulative geoecological effects of 62 years of infrastructure and climate change in ice-rich permafrost landscapes, Prudhoe Bay Oilfield, Alaska. Global change biology 20(4), 1211-1224 (2014).

26.) Makarov, V. N. \& Torgovkin, N. V. The geochemistry of anthropogenic deposits in Yakutsk. Earth's Cryosphere, 22(3), 24-35 (2018).

27.) Vonk, J. E. et al. Reviews and syntheses: Effects of permafrost thaw on Arctic aquatic ecosystems. Biogeosciences 12(23), 7129-7167 (2015).

28.) Gädeke, A. et al. Climate change reduces winter overland travel across the Pan-Arctic even under lowend global warming scenarios. Environmental Research Letters 16(2), 024049 (2021). 
29.) UNISDR. (2009) Terminology for Disaster Risk Reduction, https://www.undrr.org/publication/2009unisdr-terminology-disaster-risk-reduction, accessed 23 February 2022.

30.) Bartsch, A. et al. Expanding infrastructure and growing anthropogenic impacts along Arctic coasts. Environmental Research Letters 16(11), 115013 (2021).

31.) Schneider von Deimling, T. et al. Consequences of permafrost degradation for Arctic infrastructurebridging the model gap between regional and engineering scales. The Cryosphere 15(5), 2451-2471 (2021).

32.) Fei, X., Fang, M. \& Wang, Y. Climate change affects land-disposed waste. Nature Climate Change 11(12), 1004-1005 (2021).

33.) Wang, Z. et al. We need a global science-policy body on chemicals and waste. Science 371(6531), 774-776 (2021).

34.) Schaefer, K. et al. Potential impacts of mercury released from thawing permafrost. Nature communications 11(1), 1-6 (2020).

35.) Kokelj, S. V. Drilling Mud Sumps in the Mackenzie Delta Region: Construction, Abandonment and Past Performance. GeoNorth Limited (2002).

36.) Haklay, M. \& Weber, P. Openstreetmap: User-generated street maps. IEEE Pervasive computing 7(4), 12-18 (2008).

37.) Schultz, M., Voss, J., Auer, M., Carter, S. \& Zipf, A. Open land cover from OpenStreetMap and remote sensing. International journal of applied earth observation and geoinformation 63, 206-213 (2017).

38.) Barron, C., Neis, P. \& Zipf, A. A comprehensive framework for intrinsic OpenStreetMap quality analysis. Transactions in GIS 18(6), 877-895 (2014).

39.) Runkler, T. A. \& Bezdek, J. C. Automatic keyword extraction with relational clustering and Levenshtein distances. In Ninth IEEE International Conference on Fuzzy Systems. FUZZ-IEEE 2000 (Cat. No. 00CH37063), IEEE 2, 636-640 (2000).

40.) Baddeley, A. Analysing spatial point patterns in R. Technical report, CSIRO, 2010. Version 4 (2008).

41.) Baddeley, A. J., Møller, J. \& Waagepetersen, R. Non- and semi-parametric estimation of interaction in inhomogeneous point patterns. Statistica Neerlandica 54(3), 329-350 (2000).

42.) Langer, M., Westermann, S., Heikenfeld, M., Dorn, W. \& Boike, J. Satellite-based modeling of permafrost temperatures in a tundra lowland landscape. Remote Sensing of Environment 135, 12-24 (2013). 
43.) Westermann, S. et al. Transient modeling of the ground thermal conditions using satellite data in the Lena River delta, Siberia. The Cryosphere 11(3), 1441-1463 (2017).

44.) NCAR, CLM4.0 Offline Model Forcing Data Archived from CCSM4 historical and RCP simulations. Available online: http://www.cesm.ucar.edu/models/cesm1.0/clm/clm_ccsm4forcingdata_esg.html (2016), accessed on 7 July 2020.

45.) Lange, S. EartH2Observe, WFDEI and ERA-Interim data Merged and Bias-corrected for ISIMIP (EWEMBI) [Data set] GFZ Data Services https://doi.org/10.5880/pik.2019.004 (2019).

46.) Phipps, S. J. et al. Paleoclimate data-model comparison and the role of climate forcings over the past 1500 years. Journal of Climate 26(18), 6915-6936 (2013).

47.) Faroux, S. et al. ECOCLIMAP-II/Europe: A twofold database of ecosystems and surface parameters at $1 \mathrm{~km}$ resolution based on satellite information for use in land surface, meteorological and climate models. Geoscientific Model Development 6(2), 563-582 (2013).

48.) Masson, V., Champeaux, J. L., Chauvin, F., Meriguet, C. \& Lacaze, R. A global database of land surface parameters at 1-km resolution in meteorological and climate models. Journal of climate 16(9), 1261-1282 (2003).

49.) Hugelius, G. et al. The Northern Circumpolar Soil Carbon Database: spatially distributed datasets of soil coverage and soil carbon storage in the northern permafrost regions. Earth System Science Data 5(1), 3-13 (2013).

50.) Pelletier, J. D. et al. A gridded global data set of soil, intact regolith, and sedimentary deposit thicknesses for regional and global land surface modeling. Journal of Advances in Modeling Earth Systems 8(1), 41-65 (2016).

51.) Le Moigne, P. et al. SURFEX scientific documentation. Note de centre (CNRM/GMME), Météo-France, Toulouse, France (2009).

52.) Fan, Y., Li, H. \& Miguez-Macho, G. Global patterns of groundwater table depth. Science 339(6122), 940-943 (2013).

53.) Sturm, M. et al. Estimating snow water equivalent using snow depth data and climate classes. Journal of Hydrometeorology 11(6), 1380-1394 (2010).

\section{Declarations}

\section{Acknowledgments:}

The authors acknowledge the support of Michael Auer from the Heidelberg Institute for Geoinformation Technology (HeiGIT) for providing the OSMlanduse data. We thank Stephan Jacobi for supporting us 
with graphical design of the figures. We acknowledge the support of Alexander Oehme for processing the climate forcing data and helping to layout the figures and the manuscript.

This work was supported by a grant from the German Federal Ministry of Education and Research (BMBF) awarded to M.L (project PermaRisk, grant no. 01LN1709A). The work was also supported by the IceRoads project funded by the AWI Innovations Fonds (Innovation Project IP10200006). S.W. acknowledges funding through the Research Council of Norway (project PERMANOR, grant no. 255331) and Nunataryuk (EU grant agreement no. 773421). R.Rolph was supported by the Geo.X, the Research Network for Geosciences in Berlin and Potsdam (grant no. SO_087_GeoX). G.G. acknowledges support from EU Arctic Passion.

\section{Author Contributions:}

M. L. designed the study, performed the data analysis, carried out the panarctic simulations and analyses, prepared the figures and led the paper preparation. T. S.v.D. and G. G. co-designed the study and interpreted the results. S. M. helped with result interpretation and contributed to the development of the numerical models. R. Rolph provided background data on industrial contaminations in permafrost environments. R. Rutte performed the analysis of chemicals and environmental toxicities and provided important information on industrial infrastructure and waste management practices in the Arctic. M. S. provided interpretation and evaluation of land use data from OSM. V. R. provided input on the current environmental policy framework in the Arctic. All authors contributed to the writing and editing of the paper.

\section{Competing Interest Statement:}

The authors declare no competing interests.

\section{Figures}



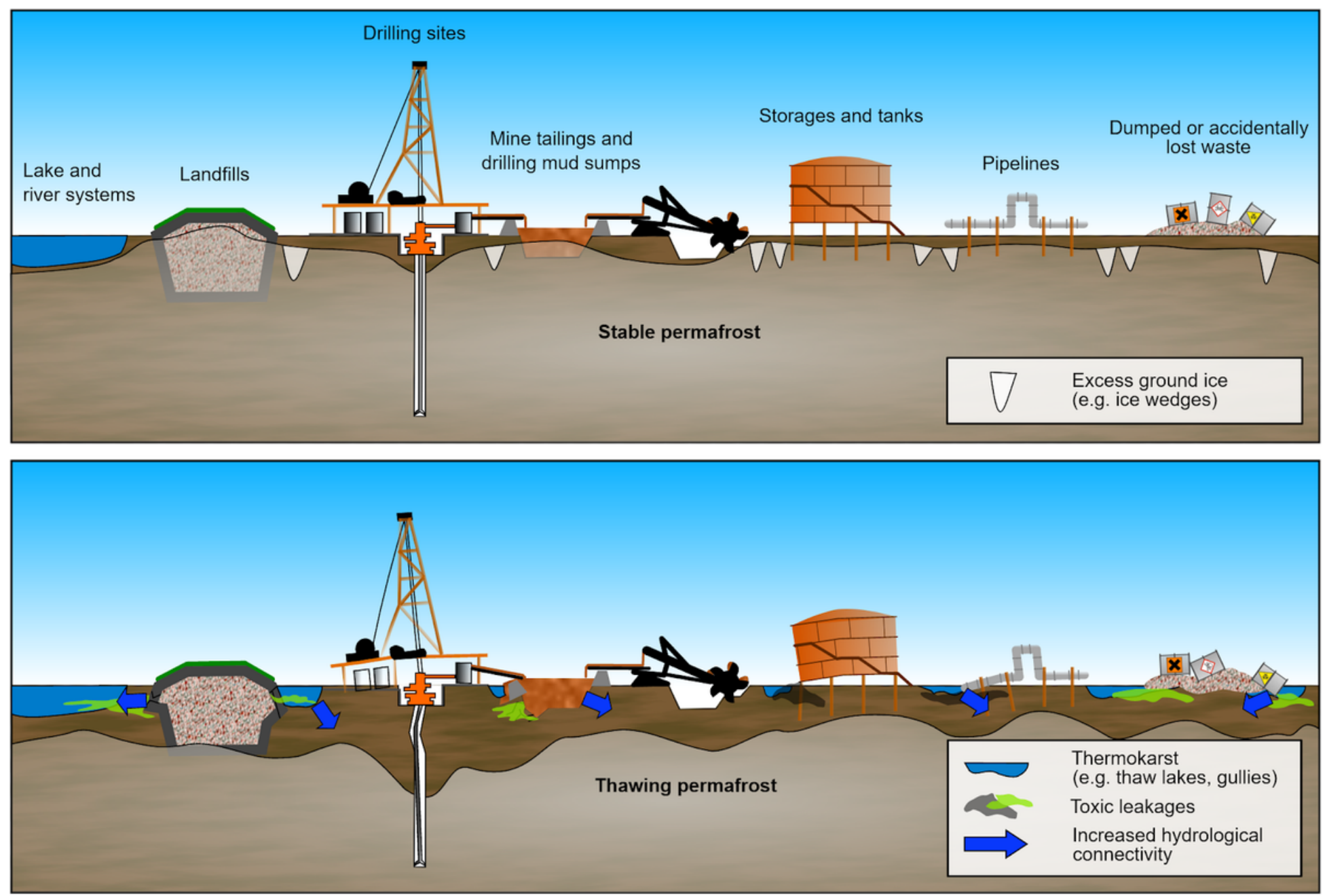

\section{Figure 1}

The potential impacts of thawing permafrost on above and below ground industrial infrastructure containing toxic substances or waste. The deepening of the thaw layer at the surface (active layer) unlocks frozen disposal sites, destabilizes foundations and containment structures. Furthermore, permafrost thaw intensifies thermo-hydrological erosion and increases the lateral flow of water, fostering the dispersion of contaminants. 


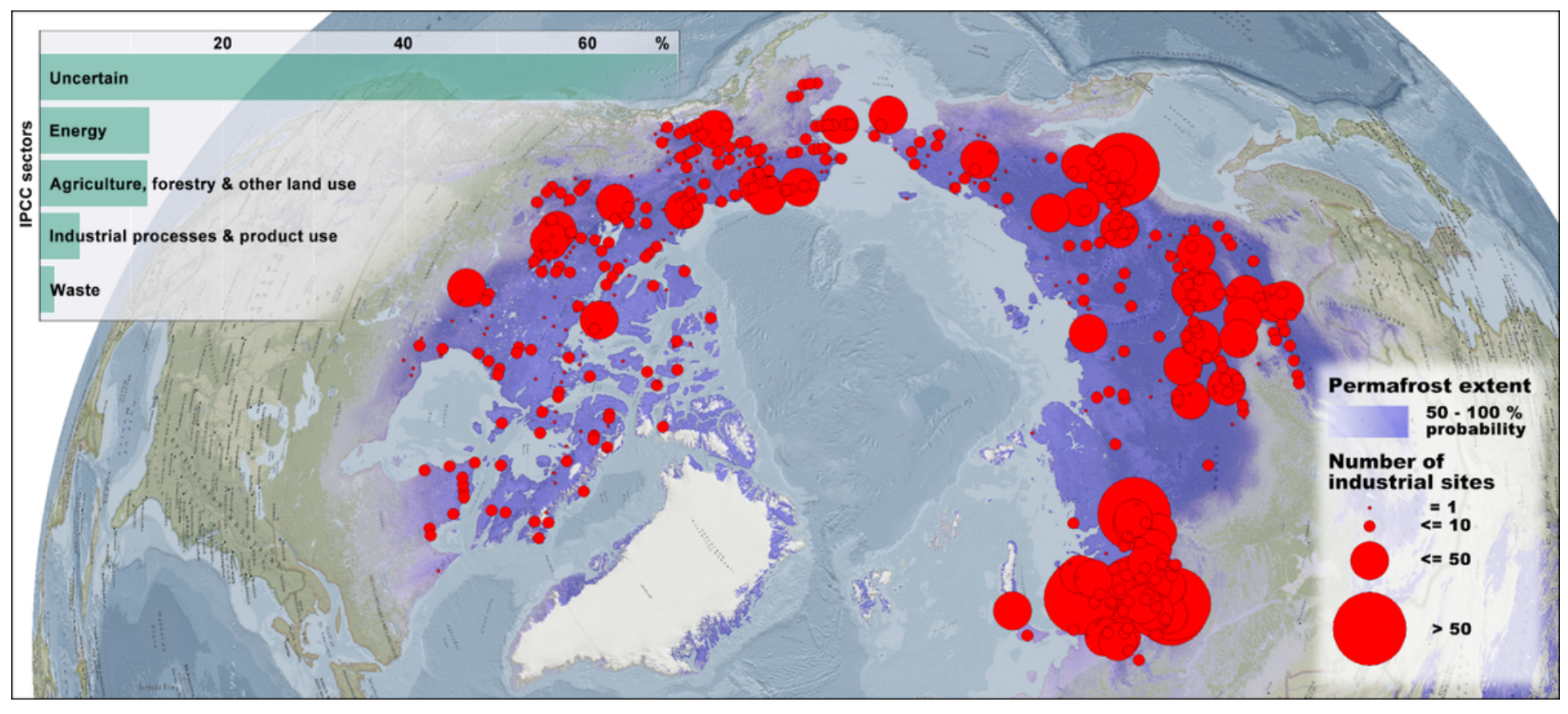

\section{Figure 2}

The occurrence of data labels indicating industrial facilities that are potentially associated with toxic substances within modeled zones of continuous and discontinuous permafrost (22). Our new database synthesizes data from OpenStreetMap (OSM) and the Nordregio Atlas of population, society and economy in the Arctic from 2019. More than $60 \%$ of the mapped industrial facilities are not labeled according to one of the IPCC industrial sector classes, indicating the large uncertainty concerning the presence of toxic substances. Only a small fraction of sites have a clear denomination as an industrial 'Waste' location. 


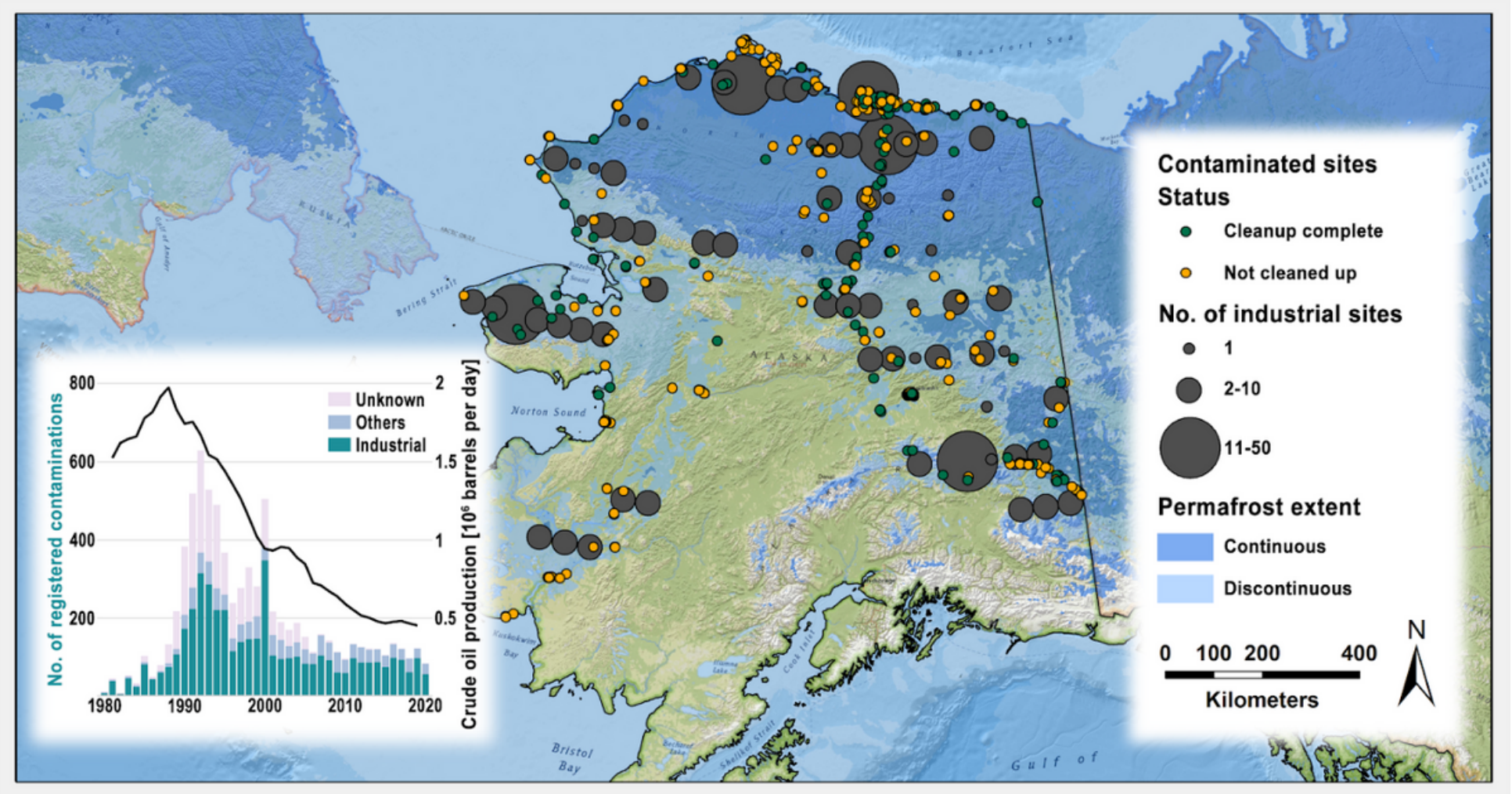

\section{Figure 3}

The distribution of industrial and contaminated sites in Alaska as reported by the Contaminated Sites Program (CSP) of the Department of Environmental Conservation. The labels "Not cleaned up" and "Cleanup complete" refer to the information whether hazardous substances remained in the environment or were removed. The inset figure shows the number of contaminations according to the first date of registration within the CSP together with quantities of crude oil production on the North Slope as provided by the U.S. Energy Information Administration (EIA). 


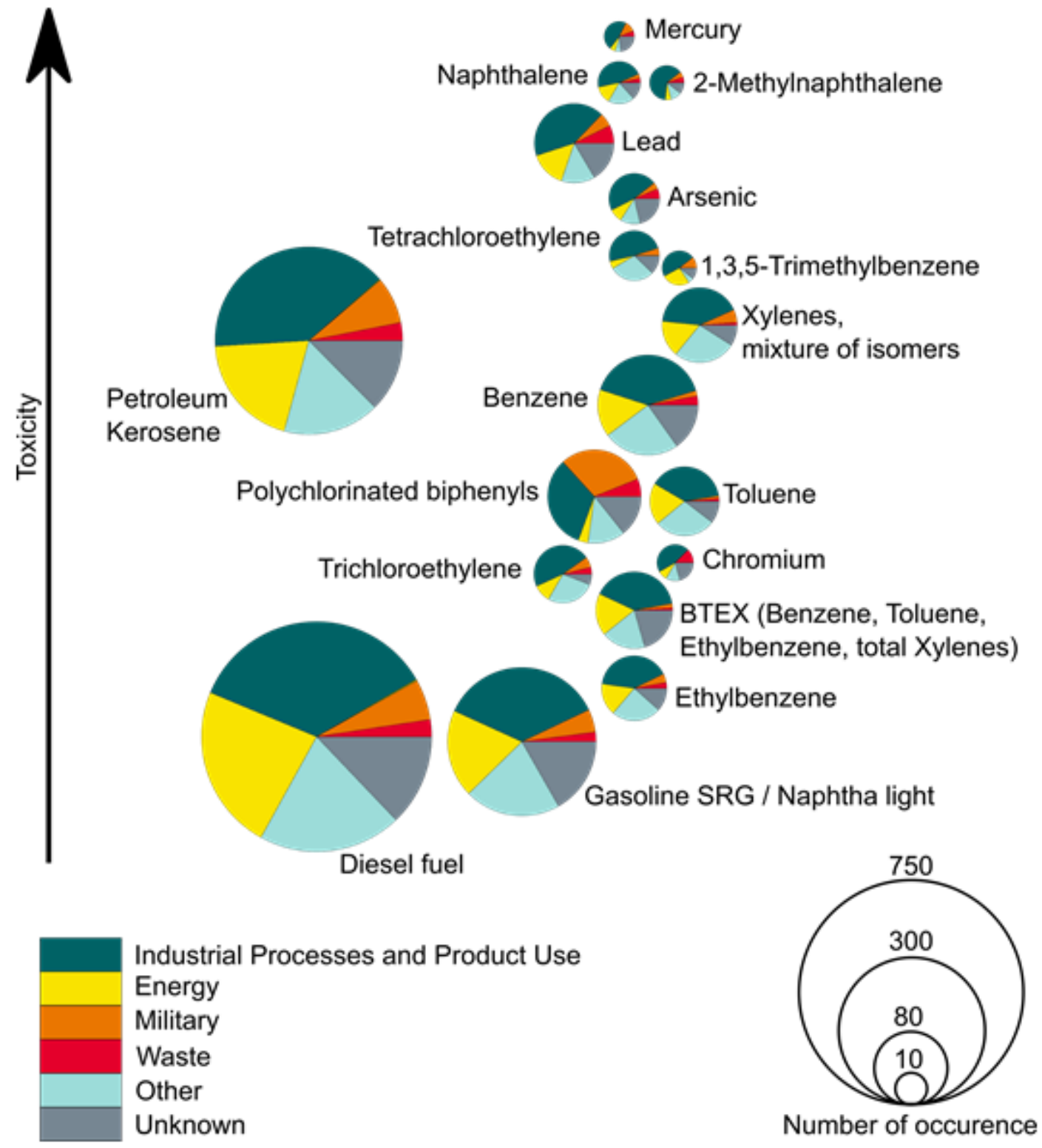

\section{Figure 4}

Most frequently occurring toxic substances at contaminated sites in permafrost in Alaska as reported by the Contaminated Sites Program (CSP). The occurrence is further differentiated according to the industrial sectors Industrial Processes and Product Use (IPPU), Energy, Military, and Waste. Toxic substances from Agriculture, Forestry, and Other Land Use (AFOLU) occur in negligible numbers. Substances are ranked relatively according to their toxicity, which was assessed using the median lethal concentration for fish ( $\mathrm{LC}_{50}$-fish) after 96 hours (see also SI Appendix, Fig. S2 and Tab. S2). 

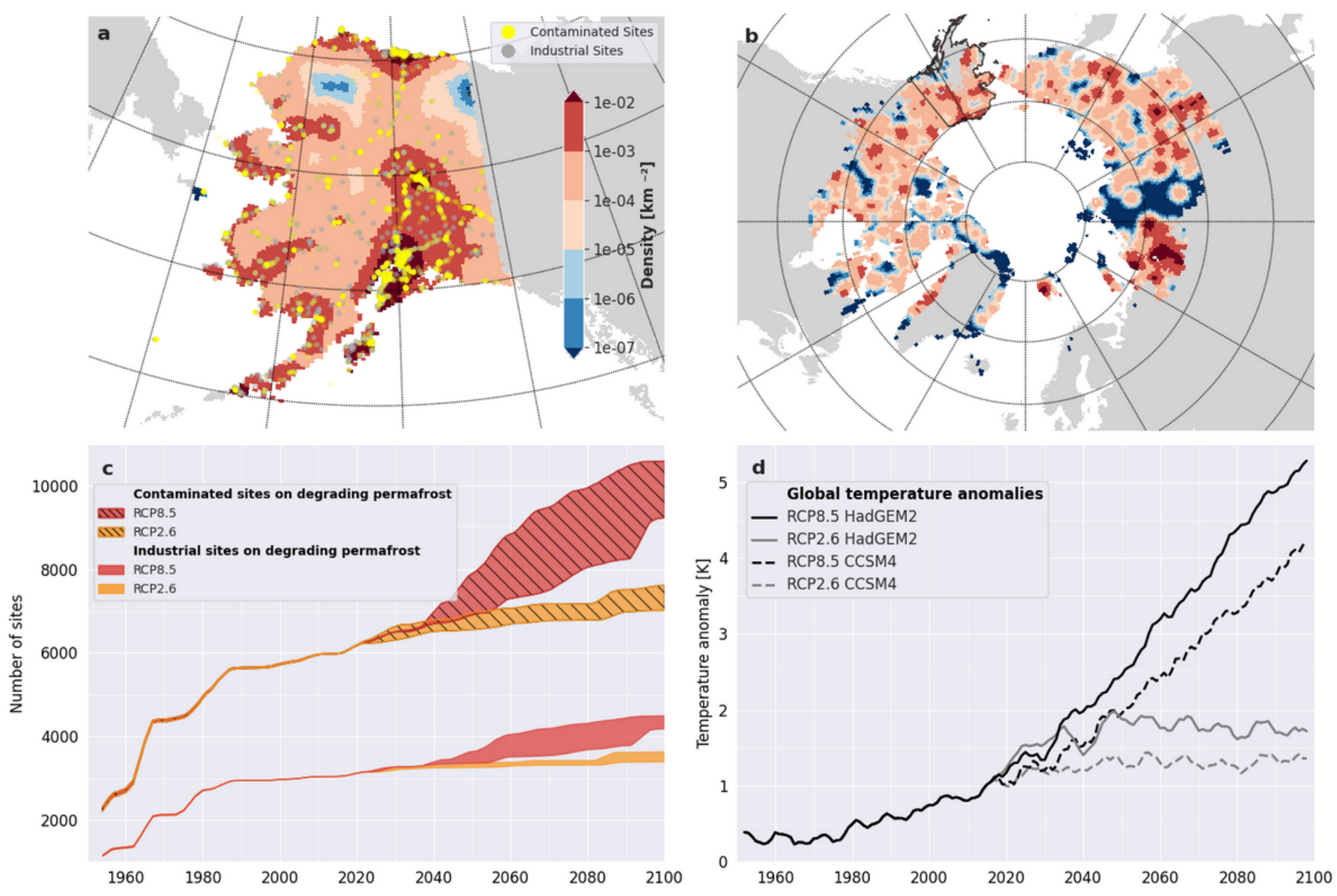

\section{Figure 5}

Density maps of contaminated sites per area as derived by the point process model for (a) Alaska with points depicting the locations of industrial and contaminated sites and (b) the entire Arctic permafrost domain. Number of industrial sites and number of upscaled contaminated sites for the entire Arctic located on degrading permafrost according to RCP 2.6 and RCP 8.5 warming scenarios spanned by CCSM4 and HADGEM2-ES CMIP5 projections (c). The global temperature anomalies refer to warming above pre-industrial levels (1850-1900) (d). 


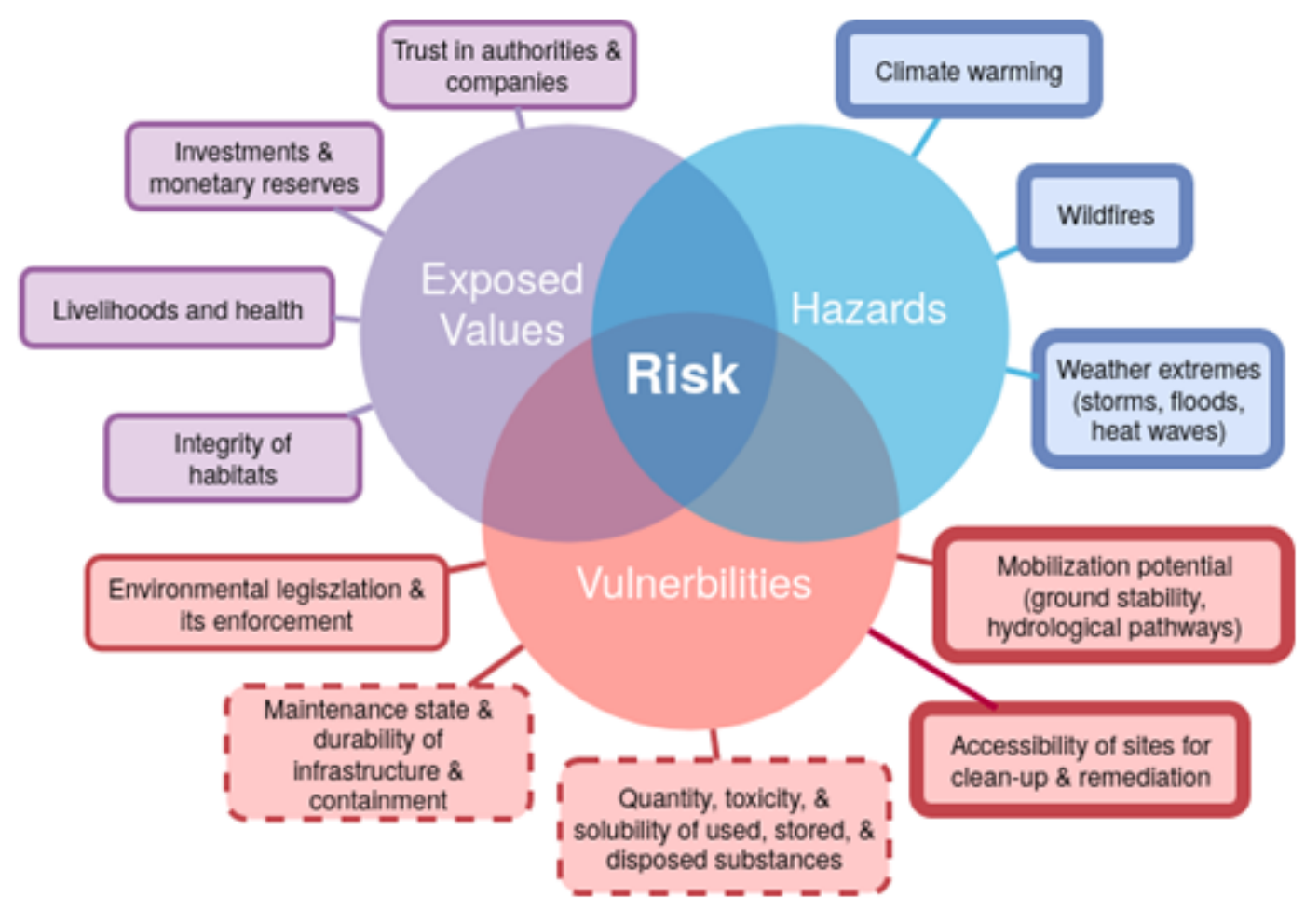

\section{Figure 6}

Summary and classification of the discussed factors controlling the environmental, economic, and social risks associated with industrial contamination in the Arctic permafrost regions. The applied classification follows the definitions proposed by the United Nations (29). Factors which are subject to large uncertainty due to undisclosed or lacking information are marked by a dashed outline. Factors that directly or indirectly affect permafrost stability or are affected by permafrost thaw are marked by bold outlines.

\section{Supplementary Files}

This is a list of supplementary files associated with this preprint. Click to download.

- supplementaryinformation.doc 